\title{
Hydroxyl Radical Probe of the \\ Calmodulin-Melittin Complex Interface by Electrospray Ionization Mass Spectrometry
}

\author{
Jason W. H. Wong \\ School of Molecular and Microbial Biosciences, The University of Sydney, Sydney, Australia \\ Simin D. Maleknia \\ School of Science, Griffith University, Brisbane, Australia
}

Kevin M. Downard

School of Molecular and Microbial Biosciences, The University of Sydney, Sydney, Australia

The calcium-dependent interaction of calmodulin and melittin is studied through the application of a radical probe approach in which solutions of the protein and peptide and protein alone are subjected to high fluxes of hydroxyl and other oxygen radicals on millisecond timescales. These radicals are generated by an electrical discharge within an electrospray ion source of a mass spectrometer. Condensation of the electrosprayed droplets followed by proteolytic digestion of both calmodulin and melittin has identified residues in both which participate in the interaction and/or are shielded from solvent within the protein complex. Consistent with other theoretical models and available experimental data, the tryptophan residue of melittin at position 19 is shown to be critical to the formation of the complex with the C-terminal domain of peptide enveloped by and protected from oxidation upon binding to the protein. Furthermore, the N-terminal domain (to residue 36) and tyrosine at position 99 in calmodulin are significantly protected from limited oxidation upon the binding of melittin while exposing the phenylalanine residue at position 92 of the flexible loop domain. The N-terminus (through residue 36) of calmodulin is shown to lie in closer proximity to the melittin helix than its C-terminal counterpart (residues 127-148) based upon the protection levels measured at reactive residues within these segments of the protein. (J Am Soc Mass Spectrom 2005, 16, 225-233) (C) 2004 American Society for Mass Spectrometry

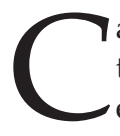
almodulin is a ubiquitous eukaryotic protein that regulates the activity of a wide variety of enzymes through its binding to them in the presence of calcium [1, 2]. The interaction between calmodulin and a target protein is a key step in many calcium-regulated cellular functions [3, 4]. Calmodulin has also been shown to be able to bind a wide range of smaller ligands, including polypeptides, in which the interaction takes place between amino acid side chains $[5,6]$. Peptides with little sequence homology, however, are capable of binding to calmodulin, though the majority of peptides that do so have a high propensity to form an amphipathic $\alpha$-helix [7,8] and contain a cluster of basic residues.

The interaction between calmodulin and the $\alpha$-helical peptide melittin has been the subject of a number of investigations over the years using a range of spectroscopic approaches [9-17]. Fluorescence and circular di-

Published online December 21, 2004

Address reprint requests to Dr. K. Downard, School of Molecular and Microbial Biosciences, G-08, The University of Sydney, Sydney, NSW 2006, Australia. E-mail: kdownard@usyd.edu.au chroism spectroscopy have revealed that in the presence of calcium, both calmodulin and melittin undergo significant structural changes, particularly in the vicinity of tyrosine residues 99 and 138 in calmodulin and at tryptophan 19 in melittin [9]. Small angle X-ray scattering has also identified significant structural changes in calmodulin with its transformation from a dumbbell to globular conformation upon its binding to melittin [13]. Similar conclusions have been drawn from limited proteolysis experiments followed by mass spectrometric analysis [16].

Despite an earlier report on the successful growth of crystals of the calmodulin-melittin complex containing bound calcium [18], no X-ray crystallographic data have been made publicly available. X-ray crystal data for other calmodulin-peptide complexes, however, have been obtained [19] and the structure of the calmodulinmelittin complex predicted [16] based on this data and proton NMR studies for the unbound protein [20]. Nonetheless, to-date there exists no high-resolution experimental data for the calmodulin-melittin complex that represents an important model of calmodulin target recognition.

To explore further the interaction between this im- 
portant protein and the peptide melittin, we have applied an approach developed over a number of years to probe protein structure and interactions using oxygen-based radicals [21-28]. Briefly, proteins or their complexes are treated with a high flux of radicals on millisecond timescales that results in the limited (less than a few percent) oxidation of individual amino acid side chains. It has been found that where the reaction timescales are short (less than 10-30 ms), the extent of oxidation at reactive amino acid residue side chains is highly influenced by the accessibility of these sites to the bulk solvent [21-28]. This would not be the case were the structure of the protein or complex to be perturbed. A quantitative measure of the level of oxidation at all reactive residues across the protein sequence enables a map of the surface of the protein or an interaction interface to be derived.

Initially, radicals were produced on these fast timescales through the radiolysis of dilute peptide and protein solutions with synchrotron radiation [29]. We have since discovered a more convenient source of radicals through the application of an electrical discharge within the electrospray ion source of a mass spectrometer [21, 24, 25, 27, 28]. A similar flux of hydroxyl and other oxygen radicals are produced that react with proteins in solution at the needle tip and within the electrosprayed solution droplets. Comparable oxidation levels are effected by either method; the latter discharge approach enables the products to be analyzed directly by mass spectrometry.

This radical based approach coupled to mass spectrometric analysis [21-29] requires minimal (nanogram) levels of protein, can be applied to protein mixtures without their purification, and is capable of providing protein structure information with single amino acid resolution (at reactive residues) with relatively high sample throughput. The method has been successfully applied to follow the dynamics of protein folding at both the global and local level [23] and subsequently to several protein complexes $[25,27,28] .{ }^{\circ} \operatorname{In}^{\circ}$ the $^{\circ}$ case $^{\circ}$ of protein-protein complexes, the interaction can be mapped at either or both of the binding partners based upon the reduced levels of oxidation measured at reactive amino acid residue side chains within the interface.

In this article, we report for the first time the application of the discharge-based approach to probe a metal ion-dependent complex interaction calmodulin and melittin for which no high resolution structure exists. Structural features of the complex obtained from the data generated in this study are discussed in light of information obtained by other approaches.

\section{Materials and Methods}

Calmodulin from bovine brain (95\%) and melittin from honey bee venom (minimum 85\%) were purchased from Sigma-Aldrich Corporation (St. Louis, MO) and used without further purification.

\section{Radical-Induced Oxidation of Mixtures of Calmodulin and Melittin}

Mixed solutions of calmodulin and melittin each at a final concentration of $50 \mu \mathrm{M}$, together where necessary with peptides insulin A chain and adrenocorticotropic hormone (ACTH) residues $18-39$ also at $50 \mu \mathrm{M}$, were prepared in $5 \mathrm{mM}$ ammonium acetate (at $\mathrm{pH} 7$, or adjusted to $\mathrm{pH} 4$ ) containing $300 \mu \mathrm{M}$ calcium acetate. These solutions were infused into the electrospray ion source of an LCQ quadrupole ion trap mass spectrometer (Thermofinnigan, San Jose, CA) at a rate of $8 \mu \mathrm{l} / \mathrm{min}$ operated with a needle voltage of $8 \mathrm{kV}$. Oxygen was used as the sheath gas at a regulator pressure of $250-350 \mathrm{kPa}$ corresponding to a flow rate of approximately 101/ $\mathrm{min}$. Oxidized protein and peptide(s) were analyzed directly by mass spectrometry or following condensation of the electrosprayed droplets into an aluminium-capped sample tube.

\section{Enzymatic Digestion of Calmodulin and Melittin}

Collected mixed solutions of oxidized calmodulin and melittin were digested with either modified trypsin or a mixture of modified trypsin and chymotrypsin (Roche Diagnostics, Mannheim, Germany) at between 1 to $2 \%$ by weight for $15 \mathrm{~h}$ at $37^{\circ} \mathrm{C}$ in $5 \mathrm{mM}$ ammonium acetate $(\mathrm{pH}$ 7). Protein-peptide digests were analyzed in LCMS, ion-intensity dependent MS/MS, and MALDI-MS experiments.

\section{Reverse-Phase LC-MS of Peptide Mixtures and Proteolytic Digests}

Collected protein and peptide samples and their digests were analyzed using a high pressure, liquid chromatography (HPLC) system (Spectra Physics, Model 4000, San Jose, CA) coupled to the ESI source of an LCQ quadrupole ion trap mass spectrometer (Thermofinnigan, San Jose, CA) via a UV detector (Spectra Physics, Model 6000). Reverse-phase chromatography was performed on a $1 \times 150 \mathrm{~mm} \mathrm{C}_{18}$ column (Vydac Separations Group Inc., Hesperia CA) at a flow rate of $50 \mu \mathrm{L} / \mathrm{min}$ by means of an Acurate (LC Packings, Sunnyvale CA) solvent flow splitter. Peptides were eluted from the column using a $5 \%$ gradient of acetonitrile and water each containing acetic acid $(0.1 \%$ by volume $)$ and TFA $(0.01 \%$ by volume). All mass spectral data were recorded in the profile mode. The level of oxidation was measured based on the area under the selected ion chromatographic traces generated for each peptide in its oxidized and unoxidized form across all charge states.

MS/MS spectra were generated for preselected ions or the most abundant ions per scan in the ion-intensity dependent mode. Precursor ions were dissociated through their collision with helium gas in the ion trap at a collision energy setting of 25-40 (arbitrary units). 


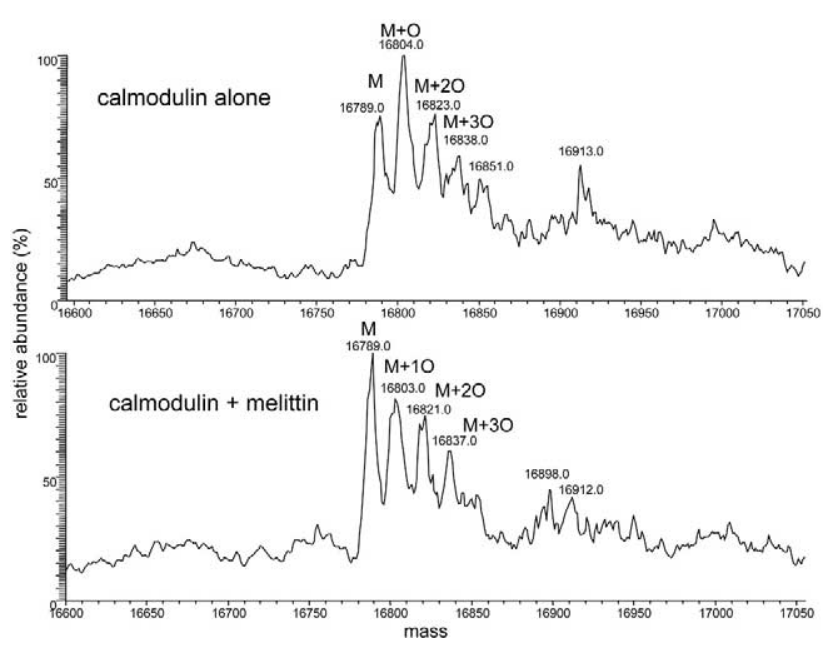

Figure 1. Deconvoluted (by molecular weight) ESI mass spectrum of calmodulin oxidized by electrical discharge in the absence (top) and presence (bottom) of melittin.

Both $^{\circ} \mathrm{ESI}^{-\mathrm{MS}^{\circ}}$ and $^{\circ} \mathrm{MS} / \mathrm{MS}^{\circ}$ spectra $^{\circ}\left(\right.$ except $^{\circ}$ Figure $^{\circ} 6$ ) shown represent the sum of multiple scans to reduce noise and improve ion statistics.

\section{MALDI-MS Analysis of Proteolytic Digests}

The MALDI mass spectrum was recorded on an Applied Biosystems QSTAR hybrid mass spectrometer operating in the TOF-MS profile mode. The sample solution was diluted tenfold with a matrix solution containing $\alpha$-cyano-4-hydroxycinnamic acid in acetonitrile and water (70:30 by volume) containing $0.1 \%$ trifluoroacetic acid, a portion $(1 \mu \mathrm{l})$ dried onto the MALDI plate, and ablated at a laser power between 5 to $10 \%$ corresponding to $10 \mu \mathrm{J}$. The spectrum represents an average of 30 laser shots and is externally calibrated.

\section{Results}

Bovine calmodulin (Swiss-Prot ID: P62157) is comprised $^{\circ}$ of $^{\circ} 148^{\circ}$ amino $^{\circ}$ acid $^{\circ}$ residues $^{\circ}[30]^{\circ}$ of $^{\circ}$ which ${ }^{\circ} 30^{\circ}$ are potentially oxidizable under the conditions applied in these ${ }^{\circ}$ limited ${ }^{\circ}$ oxidation $^{\circ}$ experiments ${ }^{\circ}[21-29] . .^{\circ}$ Solutions of calmodulin alone and an equimolar mixture of calmodulin and melittin, both at $\mathrm{pH} 7$ in the presence of $300 \mu \mathrm{M}$ calcium, were separately oxidized within the electrical discharge source. The products were analyzed directly by mass spectrometry.

Figure $^{\circ} 1^{\circ}$ shows $^{\circ}$ the $e^{\circ}$ deconvoluted ${ }^{\circ}\left(\right.$ by $^{\circ}$ molecular weight) ESI spectrum of calmodulin in the absence and presence of melittin. Oxidation levels in calmodulin are clearly higher in the absence of melittin and most protein is shown to be present in a mono-oxidized form. The average molecular weight measured for unoxidized calmodulin of $16,789.0 \mathrm{Da}$. is in accord with that calculated where the protein $\mathrm{N}$-terminus is acetylated and lysine at position 115 is trimethylated (calculated average ${ }^{\circ}$ M.Wt. $\left.{ }^{\circ} 16,790.6^{\circ} \mathrm{Da}.\right)^{\circ}\left[16,{ }^{\circ} 30\right] .{ }^{\circ}$ The ${ }^{\circ}$ reduced ${ }^{\circ}$ level of oxidation within the protein in the presence of melittin is consistent with the protection of certain oxidizable residue side chains and/or possible conformational change upon the binding of calmodulin to melittin. The results alone, however, do not exclude the possibility that melittin merely acts as a radical sink and is partially oxidized at the expense of calmodulin. The full ${ }^{\circ} \mathrm{ESI}^{\circ}$ spectrum $^{\circ}$ from $^{\circ}$ which ${ }^{\circ}$ Figure $^{\circ} 1 b^{\circ}$ was $^{\circ}$ derived indeed exhibits dioxidized forms of melittin corresponding to the ions $[\mathrm{M}+3 \mathrm{H}+2 \mathrm{O}]^{3+}[\mathrm{M}+4+2 \mathrm{O}]$, respectively, $[\mathrm{M}+5 \mathrm{H}+2 \mathrm{O}]^{5+}$ at $m / z 959.5,720.5$, and $577.7^{\circ}$ (Figure 2 ).

To preclude the possibility that melittin is oxidized at the expense of calmodulin, the oxidation of calmodulin was studied in the presence of melittin and an equimolar mixture of two additional peptides, each of a similar molecular weight (2500 Da.) consisting of insulin A chain and the adrenocorticotropic hormone (ACTH) peptide fragment comprising residues 18-39. These protein-peptide mixtures were oxidized by electrical discharge in the electrospray ion in solutions held at $\mathrm{pH} 4$ and 7. Reported data reveals that the 1:1 calmodulin-melittin complex is stable in solutions at $\mathrm{pH}^{\circ} 6.5-7.0^{\circ}[12]^{\circ}$ but $^{\circ}$ dissociates $^{\circ}{ }^{\circ}{ }^{\circ}{ }^{\circ}$ ower ${ }^{\circ} \mathrm{pH}$.

The condensed electrosprayed solutions were subjected to LC-MS analysis and ion signals for the peptides and their oxidized counterparts identified within selected ion chromatograms (SIC) generated from the total ion chromatogram (TIC) for each nominated $\mathrm{m} / \mathrm{z}$ ratio $^{\circ}$ value $^{\circ}\left(\right.$ see $^{\circ}$ for $^{\circ}$ example, ${ }^{\circ}$ Figure $\left.^{\circ} 3\right) . .^{\circ}$ The $^{\circ}$ level ${ }^{\circ}$ of oxidation detected in each peptide was quantified according to a measure of the area from the SIC for each oxidized peptide over the sum of areas for total peptide (oxidized and unoxidized) across all multiply-charged ions. All three peptides were found to oxidize in both solutions ( $\mathrm{pH} 4$ and 7) though to different extents (see at $\mathrm{pH}^{\circ} 7^{\circ}{ }^{\circ}{ }^{\circ}$ Figure 4$)^{\circ}$ consistent $^{\circ}$ with $^{\circ}$ their ${ }^{\circ}$ range ${ }^{\circ}$ of reactive

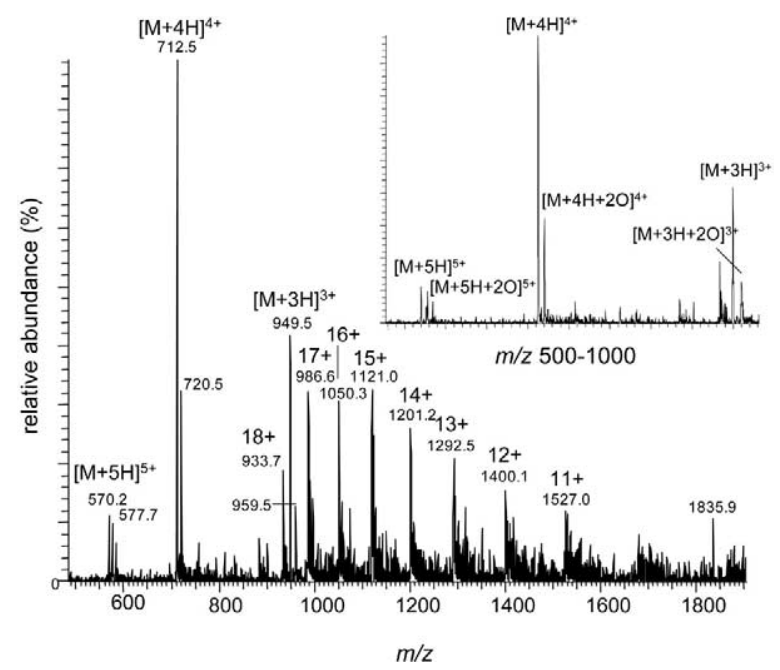

Figure 2. Full ESI mass spectrum showing the oxidation of both calmodulin and melittin and calmodulin following treatment of a solution of the complex (at $\mathrm{pH} 7$ ) with an electrical discharge. Insert shows expanded plot of ions with $\mathrm{m} / \mathrm{z}$ values $<1000$. 

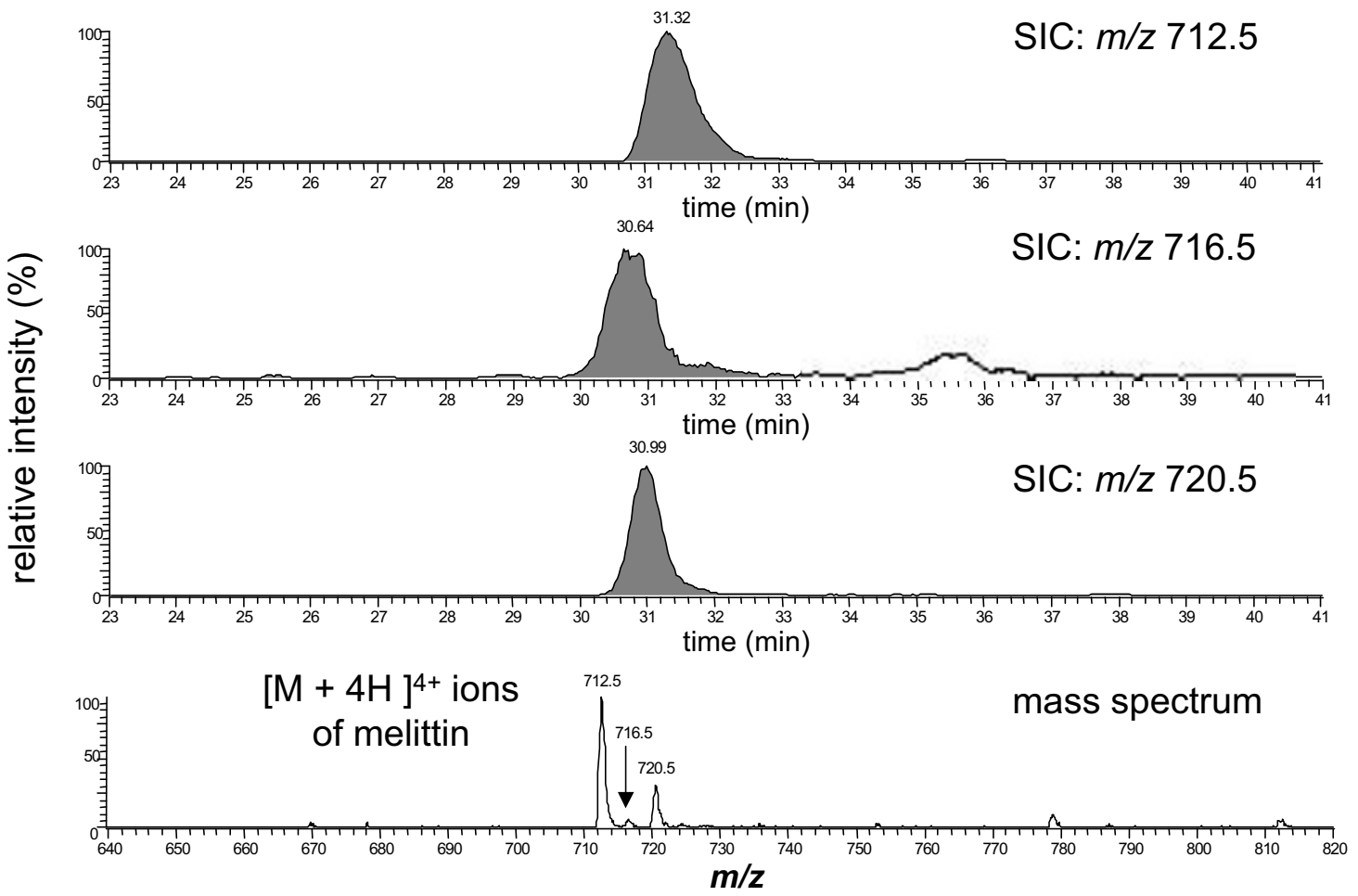

Figure 3. Areas calculated from the selected ion chromatograms illustrated for the unoxidized $\left(\mathrm{m} / \mathrm{z}\right.$ 712.5), monooxidized $(\mathrm{m} / \mathrm{z} 716.5)$, and dioxidized $(\mathrm{m} / \mathrm{z} 720.5)$ forms of the $[\mathrm{M}+4 \mathrm{H}]^{4+}$ ions of peptide melittin together with its mass spectral trace from LC-MS data.

residues. Oxidation levels based upon the area under the ion signals for the unmodified and oxidized peptides were found to be constant for peptides insulin A chain and ACTH 18-39 within experimental error at

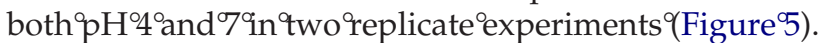
Total oxidation levels within melittin, however, were found to decrease (almost two fold to 29 from 45\%) in solutions maintained at $\mathrm{pH} 7$ relative to those at $\mathrm{pH} 4$ consistent with its selective protection upon binding to

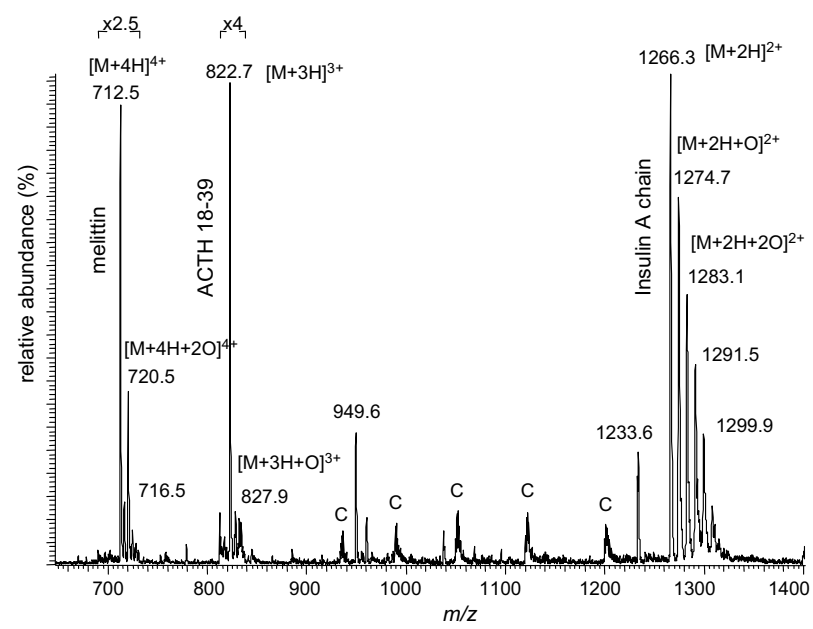

Figure 4. ESI mass spectrum showing the oxidation of melittin, insulin A chain and ACTH18-39 in the presence of calmodulin (mutliply-charged ions of charge $18+$ through $14+$ are denoted "C") at $\mathrm{pH} 7$. calmodulin. The higher levels of oxidation observed within the peptide at low $\mathrm{pH}$ (of 4) is consistent with dissociation of the calmodulin-melittin complex.

\section{Protection of Trp-19 Upon the Binding of Melittin to Calmodulin}

LC-MS experiments in conjunction with preselected ion and ion-intensity dependent MS/MS scans were performed to identify the oxidized residues in melittin and calmodulin and sites of protection after digestion of the calmodulin-melittin mixture with trypsin. Trypsin cleaves the 26 residue peptide melittin into two large

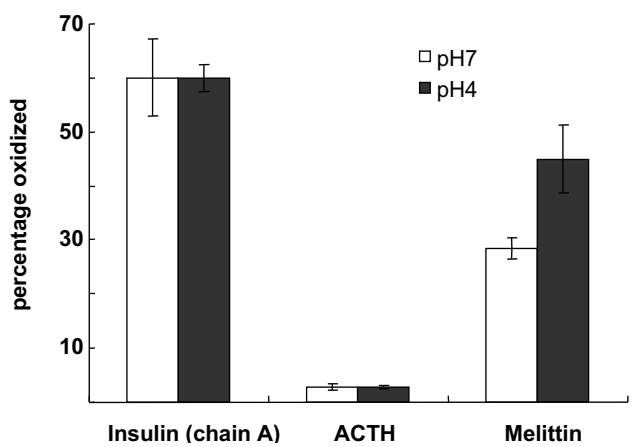

Figure 5. Oxidation levels measured for peptides melittin, insulin A chain and ACTH18-39 in the presence of calmodulin at $\mathrm{pH}$ 4 and 7 based upon the total area under the ion signals for the unmodified and oxidized peptide ions across all charge states. 
fragments (consisting of residues $1-7$ and 8-21) and several single amino acids and dipeptides toward the C-terminus. No oxidation was detected in the N-terminal fragment (residues 1-7). Ion signals for the unoxidized and dioxidized $[\mathrm{M}+2 \mathrm{H}+2 \mathrm{O}]^{2+}$ form of peptide fragment (residues 8-21) eluted at approximately 43 min. Tandem mass spectra of the $[\mathrm{M}+2 \mathrm{H}]^{2+}$ ions for the unoxidized and dioxidized peptide fragment are shown in Figure $\%$. The $m / z$ values for $b_{n}$ ions $(n=6$ and 10) that contain up to the first 10 amino acid residues from the N-terminus are identical in both spectra. The $\mathrm{m} / \mathrm{z}$ values, however, for all ions detected of the $\mathrm{y}_{\mathrm{n}}$ series ( $n$ between 4 and 12 ) as well as the $b_{13}$ and $\left(b_{14}\right)^{2+}$ ions are observed to shift up by $+32 \mathrm{u}$ in the tandem mass spectrum of the dioxidized peptide (lower spectrum, ${ }^{\circ}$ Figure $\left.^{\circ} 6\right) .{ }^{\circ}$ Collectively, ${ }^{\circ}$ this indicates that oxidation occurs within residues SWIK toward the C-terminus. Only tryptophan has been ${ }^{\circ}$ found ${ }^{\circ}$ to ${ }^{\circ}$ oxidize ${ }^{\circ}$ under the ${ }^{\circ}$ conditions $^{\circ}$ employed $^{\circ}$ in $^{\circ}$ these $^{\circ}$ experiments ${ }^{\circ}\left[21,{ }^{\circ} 24\right.$, $25,27,28]$. Similarly, no oxidation at 'isoleucine has been observed $^{\circ}[29]^{\circ}$ in $^{\circ}$ initial synchrotron-based radiolysis studies of model peptides. The oxidation of isomeric leucine and lysine has been observed in leucine/lysine rich-containing peptides $[28,29]^{\circ}$ where ${ }^{\circ}$ no ${ }^{\circ}$ other ${ }^{\circ}$ more favorable ${ }^{\circ}$ xidation $^{\circ}$ pathways $^{\circ}$ are $^{\circ}$ possible $^{\circ}[31]$. $^{\circ}$

\section{Protection of Sites within Calmodulin upon Binding to Melittin}

The levels of oxidation within tryptic peptides derived from the oxidation of calmodulin in the absence and presence of melittin were measured by LC-MS. Values for $^{\circ}$ six $^{\circ}$ oxidized $^{\circ}$ tryptic $^{\circ}$ peptides $^{\circ}$ are $^{\circ}$ shown $^{\circ}$ in $^{\circ}$ Table $^{\circ} 1$ together with one unreactive segment that serves as a control. Collectively, these segments span over $42 \%$ of the protein sequence. The six oxidizable tryptic peptides each contain sulphur (within methionine) and aromatic (within phenylalanine and tyrosine) containing amino acid residues that all have been shown to oxidize $^{\circ}$ in $^{\circ}$ our $^{\circ}$ previous $^{\circ}$ studies $^{\circ}\left[21-29\right.$ ].$^{\circ}$ Selected ${ }^{\circ}$ ion chromatograms were generated for each of the tryptic peptide ions from the digest of calmodulin oxidized alone and in the presence of melittin. The levels of oxidation within the peptides were quantified based upon the areas under the selected chromatogram for each peptide in its unoxidized and mono-oxidized form. Since peptides in their unoxidized and oxidized forms share very similar structures and $m / z$ values their ionisation and detection efficiencies are assumed to be identical. ${ }^{\top}$ The ${ }^{\circ}$ oxidation ${ }^{\circ}$ ata $^{\circ}$ are $^{\circ}$ summarized $^{\circ}$ in ${ }^{\top}$ Table 1 together with the monoisotopic $\mathrm{m} / \mathrm{z}$ values for the peptides analyzed.

\section{VLTTGLPALISWIK : melittin 8-21}

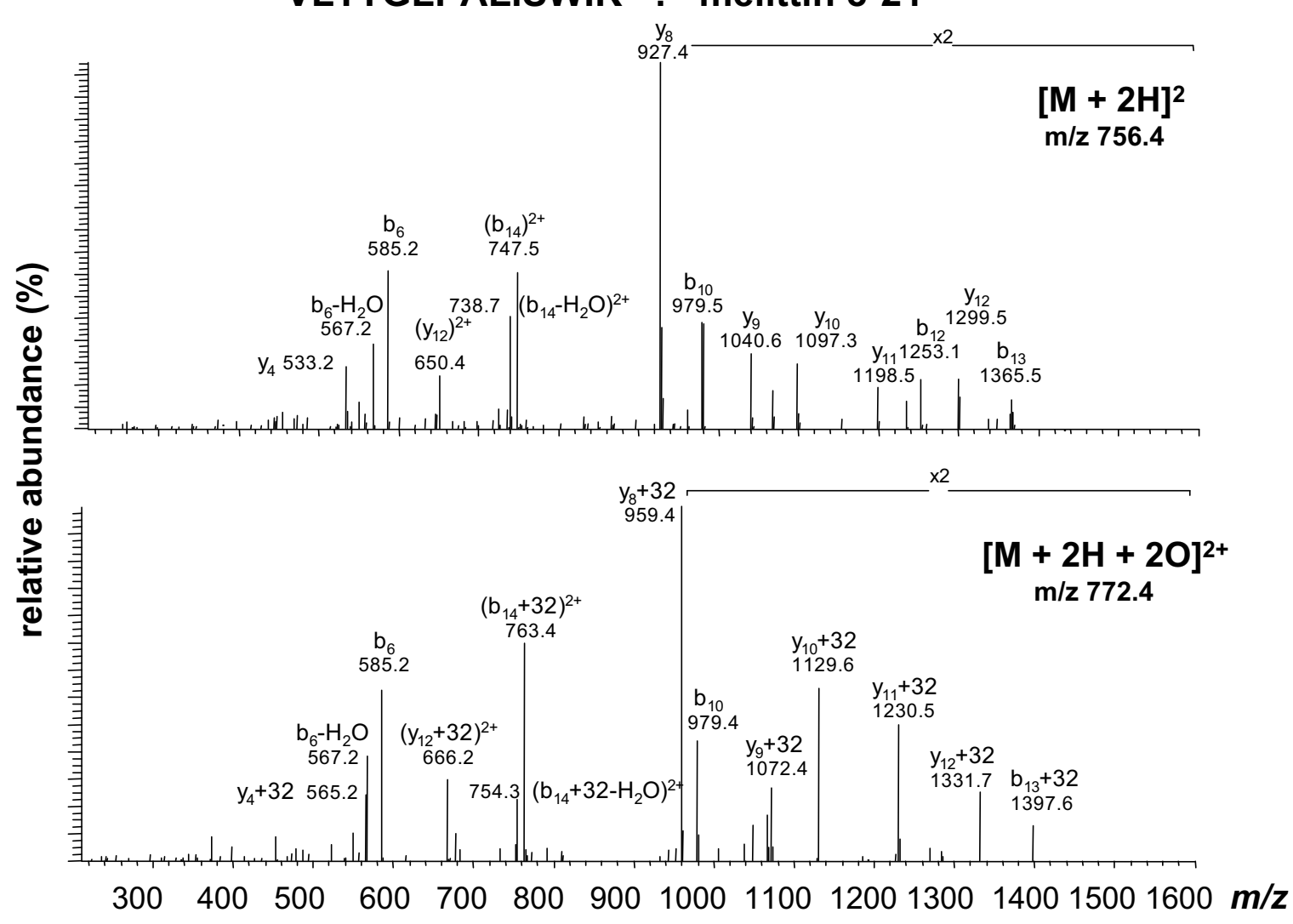

Figure 6. MS/MS spectra recorded for the doubly-charged ions of the tryptic fragment of melittin (residues 8-21) in their unoxidized (top) and dioxidized (bottom) form. 
Table 1. Oxidation levels within tryptic segments of calmodulin in the absence and presence of melittin at $\mathrm{pH} 7$

\begin{tabular}{|c|c|c|c|c|c|c|}
\hline Residues & $\begin{array}{l}\text { Sequence (Potential reactive } \\
\text { residues shown in bold }{ }^{\mathrm{a}} \text { ) }\end{array}$ & $\begin{array}{c}\mathrm{m} / \mathrm{z} \\
\text { (monoisotopic) } \\
\text { measured for } \\
{[\mathrm{M}+\mathrm{nH}]^{\mathrm{n}+}} \\
\text { ion(s) detected }\end{array}$ & $\begin{array}{c}\mathrm{m} / \mathrm{z} \\
\text { (monoisotopic) } \\
\text { measured for } \\
{[\mathrm{M}+\mathrm{nH}+} \\
\mathrm{O}]^{\mathrm{n}+} \text { ion }(\mathrm{s}) \\
\text { detected }\end{array}$ & $\begin{array}{l}\text { Percentage of } \\
\text { oxidation } \\
\text { within } \\
\text { segment } \\
\text { during } \\
\text { oxidation of } \\
\text { calmodulin } \\
\text { alone }^{b}\end{array}$ & $\begin{array}{l}\text { Percentage of } \\
\text { oxidation } \\
\text { within } \\
\text { segment } \\
\text { during } \\
\text { oxidation of } \\
\text { calmodulin } \\
\text { with melittin } \\
\text { (at pH 7) }\end{array}$ & $\begin{array}{l}\text { Protection (\%) } \\
\text { of residue } \\
\text { side chains in } \\
\text { the presence } \\
\text { of melittin }\end{array}$ \\
\hline $14-21$ & EAFSLFDK & 478.8 & $486.8(n=2)$ & $3.9 \pm 0.2$ & $1.5 \pm 0.1$ & 61.5 \\
\hline $31-36$ & ELGTVMR & 805.5 & $821.5(n=1)$ & $18.1 \pm 3.1$ & $16.1 \pm 1.1$ & 11.0 \\
\hline $78-86$ & DTDSEEEEIR & 547.2 & $555.2(n=2)$ & $0.45 \pm 0.06$ & $0.47 \pm 0.03$ & -4.4 \\
\hline $87-90$ & EAFR & 522.3 & $538.3(n=1)$ & $1.1 \pm 0.1$ & $1.1 \pm 0.1$ & 0.0 \\
\hline $91-94$ & VFDK & 508.3 & $524.3(n=1)$ & $41.9 \pm 0.6$ & $45.1 \pm 1$ & -7.6 \\
\hline $95-106$ & DGNGYISAAELR & 633.3 & $641.3(n=2)$ & $3.01 \pm 1.2$ & $0.95 \pm 0.05$ & 68.4 \\
\hline $127-148$ & EADIDGDGQVNYEEFVOMMTAK & 1245.5 & $1253.5(n=2)$ & $68.5 \pm 0.08$ & $65.9 \pm 3.8$ & 3.8 \\
\hline
\end{tabular}

aBased on published work [29]. Lysine has only been found to oxidise in lysine-rich peptides and not proteins in limited oxidation experiments [28] bValues represent the mean value obtained from repeat (at least two) experiments. Errors are recorded to one decimal place or one significant figure.

A significant degree of protection from oxidation (over $60 \%$ ) at reactive residue side chains within residues 14-21 and 95-106 of calmodulin is observed when the protein $^{\circ}$ is $^{\circ}$ oxidized $^{\circ}$ in $^{\circ}$ the ${ }^{\circ}$ presence $^{\circ}$ of $^{\circ}$ mellitin $^{\circ}\left(\right.$ Table $\left.^{\circ} 1\right)$. Far less protection is measured elsewhere in the protein ( $11 \%$ or less) across residues $31-36$ and $127-148$. This is despite the fact that both such peptide segments contain reactive methionine residues; the latter also contains reactive tyrosine and phenylalanine.
The monooxidized form of the doubly-charged ion of the tryptic peptide segment $127-148$ (at $\mathrm{m} / \mathrm{z}$ 1253.5) was dissociated in online LC-MS analysis during ionintensity ${ }^{\circ}$ dependent $^{\circ} \mathrm{MS} / \mathrm{MS}^{\circ}$ experiments $^{\circ}\left(\right.$ Figure $^{\circ} 7$ ). This MS/MS spectrum reveals that oxidation occurs at either of the methionine residues at positions 144 and 145 since all $y_{n}$ ions $(n=5-17)$ are only observed in their monooxidized form. In contrast, unoxidized $b_{n}$ ions $(\mathrm{n}=10,14,16$, and 17$)$ that contain up to 17

\section{EADIDGDGQVNYEEFVQMMTAK : calmodulin 127-148}

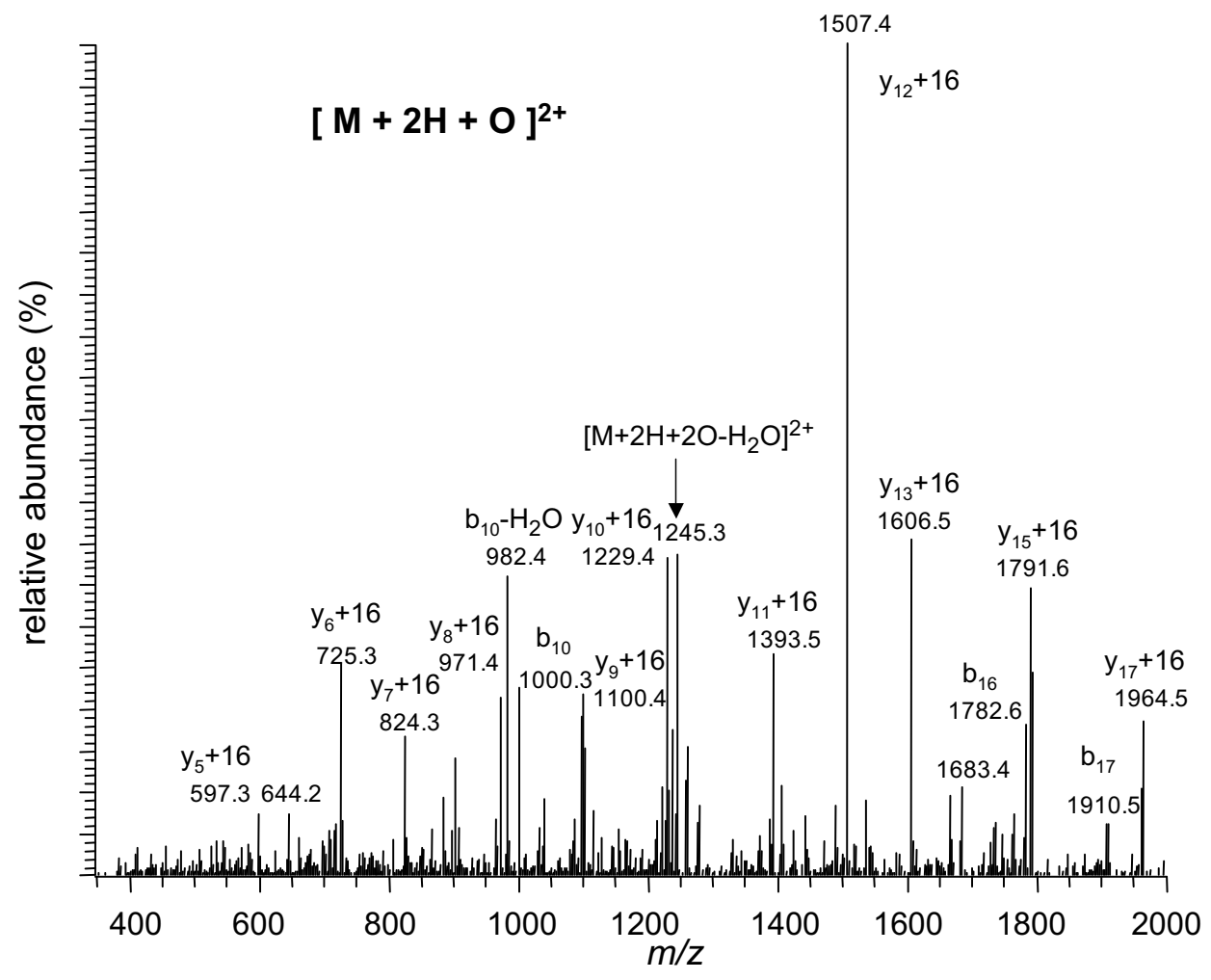

Figure 7. MS/MS spectrum of the monooxidized form of the doubly-charged $[\mathrm{M}+2 \mathrm{H}+\mathrm{O}]^{2+}$ ions of tryptic peptide ion (segment 127-148) of calmodulin. 
residues from the $\mathrm{N}$-terminus (free of both methionine residues) are observed in the absence of their monooxidized counterparts.

To confirm that the considerable oxidation of the methionine residues in this segment of the protein (total $\sim 65 \%$ ) did not mask any protection conferred to the residue side chains of tyrosine and phenylalanine at positions 138 and 141, a portion of the samples of calmodulin oxidized in the presence and absence of melittin were digested with both trypsin and chymotrypsin. Chymotrypsin should cleave the tryptic peptide segment at tyrosine 138 and phenylalanine 141 to yield three peptides comprised of residues 127-138, 139-141, and 142-148.

While the smaller peptide 139-141 (with $[\mathrm{M}+\mathrm{H}]^{+}$ ions at $m / z$ 424.2) could not be detected in either ESI or MALDI mass spectra, singly-protonated ions at $\mathrm{m} / \mathrm{z}$ 1295.5 corresponding to the peptide consisting of residues 127-138 were detected in the latter albeit of low intensity. This spectrum, however, exhibits no ions at $\mathrm{m} / \mathrm{z} 1311.5$ or above (at multiples of $+16 \mathrm{u}$ ) corresponding $^{\circ}$ to $^{\circ}$ its $^{\circ}$ oxidized $^{\circ}$ counterparts $^{\circ}\left(\right.$ Figure $\left.^{\circ} 8\right) .^{\circ}$ Although such ions may be present but do not appear above the noise level in these spectra, the combined data supports that only the methionine residue(s) at positions 144 and 145 are oxidized in this region of the protein (residues 127-148) and no statistically significant protection is conferred to it upon the binding of melittin.

\section{Discussion}

It is important to assess our data in the context of models proposed for the calmodulin-melittin complex. $\mathrm{A}^{\circ}$ popular ${ }^{\circ}$ representation ${ }^{\circ}[16]^{\circ}$ is $^{\circ}$ one $^{\circ}$ in $^{\circ}$ which $^{\circ}$ calmod- $^{-}$ ulin adopts a horseshoe-like structure in which the Nand C-terminal domains, far removed in the protein structure $^{\circ}[20],^{\circ}$ become $^{\circ}$ proximal $^{\circ}$ when $^{\circ}$ melittin $^{\circ}$ is bound. Such a model has been constructed based on NMR spectroscopic data for the calmodulin-MCLK peptide ${ }^{\circ}$ complex [32]. Like'melittin, MLCK'(a'139residue peptide segment of the myosin light chain kinase) binds calmodulin in a reverse orientation to other peptides due to the presence of a cluster of basic residues toward the C-terminus in the vicinity of tryptophan. Electrostatic interactions between the negatively charged amino acid residues of calmodulin and the cluster of basic residues within binding peptides are known to be critical $^{\circ}$ to $^{\circ}$ the $^{\circ}$ stabilization $^{\circ}$ of $^{\circ}$ the $^{\circ}$ complex $^{\circ}[16] .^{\circ}$ The backbone of calmodulin is largely orientated perpendicular to the helical axis of the melittin backboneq16]. The helical axis of melittin is proposed to be bent slightly off axis in the center of the peptide such that it adopts a banana-like shape. In the model, the side chains of Tyr-99 on calmodulin and Trp-19 of melittin are both inaccessible to solvent. This prediction is in accord with their protection from oxidation measured in this study as 68.4 and $64.4 \%$ within segment $95-106$ and melittin (Table $^{\circ} 1^{\circ}$ and $^{\circ}$ Figure $^{\circ} 5$ ). ${ }^{\circ}$ The $^{\circ}$ tryptophan $^{\circ}$ residue $^{\circ}$ is believed to be of particular importance in binding to calmodulin as it is a conserved element among known calmodulin ${ }^{\circ}$ inding ${ }^{\circ}$ peptides ${ }^{\circ}[32]$.

The shielding of tyrosine at position 99 within the complex exposes the phenylalanine residues at positions ${ }^{\circ} 89^{\circ}$ and $^{\circ} 92^{\circ}$ of $^{\circ}$ calmodulin $^{\circ}$ to ${ }^{\circ}$ the ${ }^{\circ}$ solvent ${ }^{\circ}[16]^{\circ}$ in ${ }^{\circ}$ the horseshoe model. This contrasts other calmodulin-peptide ${ }^{\circ}$ complexes $[16]^{\circ}$ and ${ }^{\circ}$ is in ${ }^{\circ}$ accord ${ }^{\circ}$ with ${ }^{\circ}$ the increase in oxidation at observed at the phenylalanine residue at position 92 (but not at position 89) measured in this work $^{\circ}\left(\right.$ Table $\left.^{\circ} 1\right)$.

The proximity of the $\mathrm{N}$ and C-termini of calmodulin to melittin in the model is assessed in this study based upon levels of oxidation within tryptic peptide segments $14-21,31-36$, and 127-148 of calmodulin. We report here protection levels of $61.5 \%$ at the side chains of oxidizable phenylalanine residues at positions 16 and 19 in tryptic peptide $14-21$. A further $11 \%$ protection was measured based on the reduced oxidation of methionine $-35^{\circ}\left(\right.$ Table $\left.^{\circ} 1\right) .{ }^{\circ}$ Further $^{\circ}$ confirmation $^{\circ}$ of ${ }^{\circ}$ the $^{\circ}$ oxidation data reported here is evident in a previous mass spectrometry study in which protection of amino acid side chains within calmodulin upon its binding to melittin was measured based on the acetylation of lysine ${ }^{\circ}$ residues $^{\circ}[14] .{ }^{\circ}$ In $^{\circ}$ this $^{\circ}$ earlier $^{\circ}$ work, ${ }^{\circ}$ protection levels of between 19 to $42 \%$ were measured across lysine residues Lys-13, 21, and 30 within calmodulin across the first 36 residues from the $\mathrm{N}$-terminus.

We have not, however, observed any significant protection within the C-terminal domain of calmodulin when it binds to melittin. Despite the high levels of oxidation within tryptic peptide segment 127-148 $(68.5 \%)$ that occurs largely at the methionine residues at positions 144 and 145, no significant reduction in oxidation is observed for the calmodulin-melittin complex $\left(3.8 \%,{ }^{\circ}\right.$ Table $\left.^{\circ} 1\right) .{ }^{\circ}$ This $^{\circ}$ is $^{\circ}$ within ${ }^{\circ}$ the ${ }^{\circ}$ experimental ${ }^{\circ}$ error $^{\circ}$ of the ${ }^{\circ}$ measurements ${ }^{\circ}\left(\right.$ Table $\left.^{\circ} 1\right)$.

We have not observed any oxidation at the tyrosine residue at position 138 or phenylalanine residue at position 141. It is conceivable that the high levels of oxidation observed at the methionine residues in tryptic peptide comprising residues 127-148 may have masked some protection of the tyrosine and phenylalanine residues, though it is unlikely for this to be the case at the C-terminal lysine residue since this residue has only been found to oxidize in studies of lysine-rich peptides [28]..$^{\circ}$ The $^{\circ}$ combined $^{\circ}$ results ${ }^{\circ}$ suggest ${ }^{\circ}$ that, ${ }^{\circ}{ }^{\circ}{ }^{\circ}$ term $s^{\circ}$ of ${ }^{\circ}$ the reactive residue side chains probed in this study, the $\mathrm{N}$-terminus of calmodulin is in closer proximity to the melittin helix than the C-terminus such that the reactivity of oxidizable residues in the former is unaffected by binding to melittin. It is important to note, however, that since the oxidation of methionine is also driven by oxygen-based radicals and oxygen in air during sample handling ${ }^{\circ}\left[25,{ }^{\circ} 26,{ }^{\circ} 29\right]^{\circ},^{\circ} \mathrm{we}^{\circ}$ are $^{\circ}$ unable $^{\circ}$ to $^{\circ}$ preclude $^{\circ}$ the possibility that there is some protection conferred by melittin upon its binding in the vicinity of this region of the ${ }^{\circ}$ protein. $^{\circ}$ Under $^{\circ}$ the $^{\circ}$ limited $^{\circ}$ oxidation $^{\circ}$ conditions employed ${ }^{\circ}$ in $^{\circ}$ these ${ }^{\circ}$ experiments $^{\circ}\left[21,{ }^{\circ} 24,{ }^{\circ} 25,{ }^{\circ} 27,{ }^{\circ} 28\right]^{\circ}$ that are necessary to prevent protein structural damage, a 


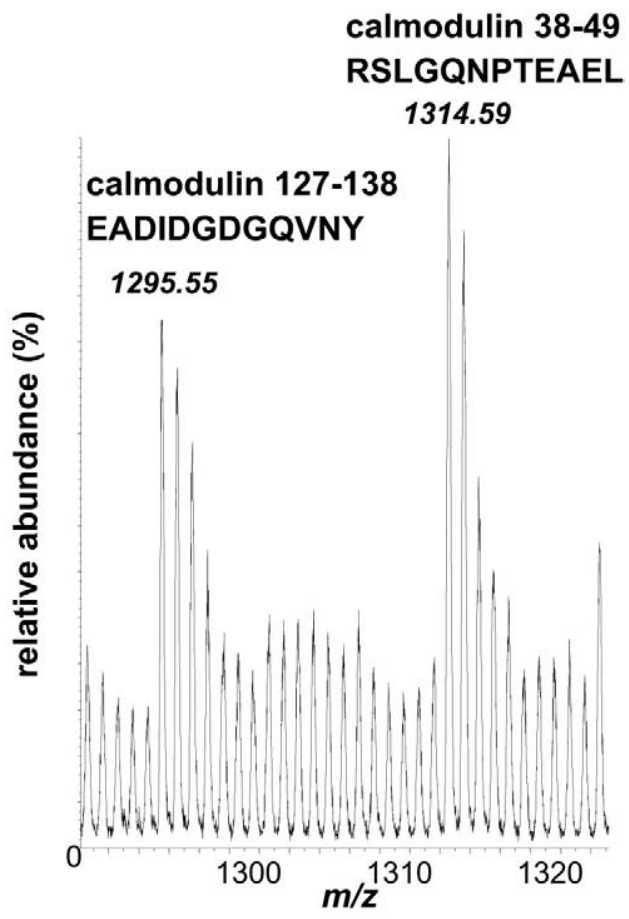

Figure 8. Region of the MALDI mass spectrum from the mixed protease (trypsin and chymotrypsin) digestion of calmodulin and melittin showing the absence of oxidation products for peptide segment 127-138 above noise.

dioxidized form of tryptic peptide segment 127-148 was detected only as a weak ion (at $\mathrm{m} / \mathrm{z} 1261.5$ ) over noise $(\mathrm{S} / \mathrm{N}$ 1.5) for which no MS/MS spectrum could be obtained.

We ${ }^{\circ}$ ave ${ }^{\circ}$ previously ${ }^{\circ}$ observed ${ }^{\circ}[21-29]^{\circ}{ }^{\circ}$ that ${ }^{\circ}$ oxidation levels can be equated with the total surface area of the reactive residue side chain where this area exceeds

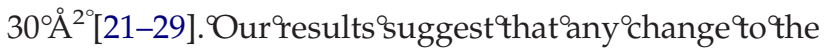
total surface area of residues Met-144 and 145, together with phenylalanine at position 141, exposed to solvent when calmodulin binds to melittin does not exceed this value.

The closer proximity of melittin to the $\mathrm{N}$-terminus over the C-terminus of calmodulin, however, is in accord $^{\circ}$ with $^{\circ} \mathrm{a}^{\circ}$ recent $^{\circ}$ published ${ }^{\circ}$ report $^{\circ}[33]^{\circ}$ that $^{\circ}$ examined the formation of cross-linked products between residue side chains. Where bifunctional intermolecular cross-linkers (of some 6.4 and $11.4 \AA$ ) were used, cross-linked products formed between the $\mathrm{N}$-terminal (residues 1-37) and center (residues 76-90) of the protein with melittin were observed over C-terminal cross-linked products. Confirmation of this observation, however, awaits a high-resolution experimental-based structure for the protein-peptide complex.

\section{Conclusions}

It has been demonstrated that the radical probe approach $^{\circ}$ we $^{\circ}$ have ${ }^{\circ}$ developed $^{\circ}\left[21,{ }^{\circ} 29\right]^{\circ}$ in $^{\circ}$ which $^{\circ}$ oxygen radicals ${ }^{\circ}$ ormed by $^{\circ}{ }^{\circ}{ }^{\circ}$ electrical ${ }^{\circ}$ discharge $\lceil 19,24,25,27$, $28]^{\circ}$ within $^{\circ}$ an $^{\circ}$ electrospray $^{\circ}$ ion $^{\circ}$ source $^{\circ}$ can $^{\circ}$ react $^{\circ}$ with protein-peptide complexes in solution to provide reliable and useful structural information concerning the interaction interface. The work described in this article demonstrates this for the first time for a calciumdependent protein-peptide complex in which the residues important to the interaction are localized within both binding partners. The results are largely in accord with a modeled horseshoe-like structure in which the $\mathrm{N}$ - and C-terminal domains of calmodulin envelope the melittin axis in the vicinity of its C-terminus about tryptophan-19. The side chain of tyrosine at position 99 is shown to be protected from the solvent within the complex, exposing the phenylalanine residue at position 92. The data has further suggested that the Nterminus of calmodulin is in closer proximity to the melittin helical axis than the C-terminus. The side chains of phenylalanine residues at positions 16 and 19, and to a lesser extent methionine at position 35, are shown to be protected from solvent upon the binding of calmodulin to melittin, while no significant protection is observed at like residues within the C-terminal domain of the protein (residues 127-148).

The radical probe approach applied in this study is envisaged to be a valuable addition to the repertoire of other experimental approaches for investigating protein-protein interactions, particularly in cases in which insufficient material or the size of the complex precludes its study by other approaches.

\section{Acknowledgments}

The authors thank Paul Smith who recorded the MALDI spectrum shown.

\section{References}

1. Klee, C. B.; Vanaman, T. C. Calmodulin. Adv. Prot. Chem. 1982, 35, 213-321.

2. Rogers, M. S.; Strehler, E. E. Guidebook to the Calcium-Binding Proteins; Oxford University Press: Oxford, UK, 1996, pp 34-40.

3. Scharff, O. Calmodulin-and its role in cellular activation. Cell Calcium 1981, 2(1), 1-27.

4. Hinrichsen, R. D. Calcium and calmodulin in the control of cellular behavior and motility. Biochim. Biophys. Acta 1993, 1155(3), 277-293.

5. Anderson, S. R.; Malencik, D. A. Peptides recognizing calmodulin. Calcium Cell Funct. 1986, 6, 1-42.

6. Clore, G. M.; Bax, A.; Ikura, M.; Gronenborn, A. M. Structure of calmodulin-target peptide complexes. Current Opin. Struct. Biol. 1993, 3(6), 838-845.

7. Strynadka, N. C. J.; James, M. N. G. Model for the interaction of amphiphilic helixes with troponin $\mathrm{C}$ and calmodulin. Prot. Struct. Funct. Genet. 1990, 7(3), 234-248.

8. Fisher, P. J.; Prendergast, F. G.; Ehrhardt, M. R.; Urbauer, J. L.; Wand, A. J.; Sedarous, S. S.; McCormick, D. J.; Buckley, P. J. Calmodulin interacts with amphiphilic peptides composed of all D-amino acids. Nature 1994, 368(6472), 651-653.

9. Maulet Y.; Cox, J. A. Structural changes in melittin and calmodulin upon complex formation and their modulation by calcium. Biochemistry 1983, 22, 5680-5686. 
10. Caday, D. G.; Steiner, R. F. The interaction of calmodulin with melittin. Biochem. Biophys. Res. Commun. 1986, 135(2), 419-425.

11. Steiner, R. F.; Marshall, L.; Needleman, D. The interaction of melittin with calmodulin and its tryptic fragments. Arch. Biochem. Biophys. 1986, 246(1), 286-300.

12. Seeholzer, S. H.; Cohn, M.; Putkey, J. A.; Means, A. R.; Crespi, H. L. NMR studies of a complex of deuterated calmodulin with melittin. Proc. Natl. Acad. Sci. U.S.A. 1986, 83(11), 36343638.

13. Kataoka, M.; Head, J. F.; Seaton, B. A.; Engelman, D. M. Melittin binding causes a large calcium-dependent conformational change in calmodulin. Proc. Natl. Acad. Sci. U.S.A. 1989, 86, 6944-6948.

14. Steiner, R. F.; Albaugh, S.; Fenselau, C.; Murphy, C.; Vestling, M. A mass spectrometry method for mapping the interface topography of interacting proteins, illustrated by the melittincalmodulin system. Anal. Biochem. 1991, 196, 120-125.

15. Nemirovskiy O. V.; Ramanathan, R.; Gross, M. L. Investigation of calcium-induced, non-covalent association of calmodulin with melittin by electrospray ionization mass spectrometry. J. Am. Soc. Mass Spectrom. 1997, 8, 809-812.

16. Scaloni, A.; Miraglia, N.; Orru, S.; Amodeo, P.; Motta, A.; Marino, G.; Pucci, P. Topology of the calmodulin-melittin complex. J. Mol. Biol. 1998, 277, 945-958.

17. Brokx, R. D.; Lopez, M. M.; Vogel, H. J.; Makhatadze G. I. Energetics of target peptide binding by calmodulin reveals different modes of binding. J. Biol. Chem. 2001, 276(17), 1408114091.

18. Tanaka, Y.; Takahashi, S.; Mitsui, Y.; Itoh, S.; Iitaka, Y.; Kasai, H.; Okuyama, T. X-ray crystallography and chromatographic characterization of the crystals of $\mathrm{Ca}^{2+}$-calmodulin complexed with bee venom melittin. J. Mol. Biol. 1985, 186, 675-677.

19. Meador, W. E.; Means, A. R.; Quiocho, F. A. Science 1992, 257, 1251-1255.

20. Ikura, M.; Spera, S.; Barbato, G.; Kay, L. E.; Krinks, M.; Bax, A. Secondary structure and side-chain $1 \mathrm{H}$ and $13 \mathrm{C}$ resonance assignments of calmodulin in solution by heteronuclear multidimensional NMR spectroscopy. Biochemistry 1991, 30, 92169228.

21. Maleknia, S. D.; Chance, M. R.; Downard, K. M. Electrosprayassisted modification of proteins. A radical probe of protein structure. Rapid Commun. Mass Spectrom. 1999, 13, 2352-2358.

22. Maleknia, S. D.; Ralston, C. Y.; Brenowitz, M. D.; Downard, K. M.; Chance, M. R. Determination of macromolecular fold- ing and structure by synchrotron X-ray radiolysis techniques. Anal. Biochem. 2001, 289, 103-115.

23. Maleknia, S. D.; Downard, K. M. Unfolding of apomyoglobin helices by synchrotron radiolysis and mass spectrometry. Eur. J. Biochem. 2001, 268, 5578-5588.

24. Maleknia, S. D.; Chance, M. R.; Downard, K. M. Electrospray generated oxygenated radicals to probe protein structure. Gelpi, E. In Advances in Mass Spectrometry; John Wiley and Sons: Chichester, U.K., 2001, pp 543-544.

25. Maleknia, S. D.; Downard, K. M. Radical approaches to probe protein structure, folding, and interactions by mass spectrometry. Mass Spectrom. Rev. 2001, 20, 388-401.

26. Maleknia, S. D.; Kiselar, J. G.; Downard, K. M. Hydroxyl radical probe of the surface of lysozyme by synchrotron X-ray radiolysis and mass spectrometry. Rapid Commun. Mass Spectrom. 2002, 16, 53-61.

27. Wong, J. W. H.; Maleknia, S. D.; Downard, K. M. Study of the ribonuclease $\mathrm{S}$ protein-peptide complex using a radical probe and electrospray ionization mass spectrometry. Anal. Chem. 2003, 75, 1557-1563.

28. Maleknia, S. D.; Wong, J. W. H.; Downard, K. M. Photochemical and electrophysical production of radicals on millisecond timescales to probe the structure, dynamics, and interactions of proteins. Photochem. Photobiol. Sci. 2004, 3, 741-748.

29. Maleknia, S. D.; Brenowitz, M. D.; Chance, M. R. Millisecond radiolytic modification of peptides by synchrotron X-rays identified by mass spectrometry. Anal. Chem. 1999, 71, 39653973.

30. Iida, Y. Molecular evolution of protein. Internal homology in the amino acid sequence of calmodulin. J. Mol. Biol. 1982, 159, 167-177.

31. Buxton, G. V.; Greenstock, C. L.; Helman, W. P.; Ross, A. B. Critical review of rate constants for reactions of hydrated electrons, hydrogen atoms, and hydroxyl radicals in aqueous solution. J. Phys. Chem. Ref. Data 1988, 270, 513-886.

32. Ikura, M.; Clore, G. M.; Gronenborn, A. M.; Zhu, G.; Klee, C. B.; Bax, A. Solution structure of a calmodulin-target peptide complex by multidimensional NMR. Science 1992, 256, 632638.

33. Schulz, D. F.; Ihling, C.; Clore, M.; Sinz, A. Mapping of the topology of a low-resolution three-dimensional structure of the calmodulin-melittin complex by chemical cross-linking and high-resolution FT-ICR. Biochemistry 2004, 43, 4703-4715. 